\title{
Characteristics of Spontaneous Supratentorial Intracerebral Hematomas: A Retrospective Analysis of 108 Consecutive Patients
}

(D) Seçkin Aydın

University of Health Sciences Turkey, Prof. Dr. Cemil Taşçıoğlu City Hospital, Clinic of Neurosurgery, Istanbul, Turkey

\section{Abstract}

Objective: Spontaneous supratentorial intracerebral hematomas (SSIH) are among the pathologies that cause serious mortality and morbidity. The objective of this study was to assess the demographic and clinical characteristics, treatment approaches and outcomes of SSIH patients.

Methods: We retrospectively analyzed 108 patients who were diagnosed with SSIH between December 2017 and December 2018.

Results: Eighty nine (82.4\%) of 108 patients were treated conservatively and 19 (17.6\%) patients were treated surgically. Fifty seven (52.8\%) of the patients were male and 51 (47.2\%) were female. The mean age was $64.5 \pm 14.0$. The mean Glasgow Coma scale (GCS) of the patients was $12.3 \pm 3.0$, and the GCS of the surgical group was significantly lower than the conservative group $(p<0.05)$. The mean hematoma volume was $40.1 \pm 51.6 \mathrm{~mL}$, and the hematoma volume in the surgical group was significantly higher than the conservative group ( $p<0.05)$. Intraventricular hemorrhage and midline shift positivity were significantly higher in the surgical group $(p<0.05)$. The mean Intracerebral Hematoma score (IHS) of the patients was $1.3 \pm 1.4$. IHS was significantly higher in the surgical group $(p<0.05)$. Mortality rates in the first month, sixth month and first year were significantly higher in the surgical group $(p<0.05)$.

Conclusion: Because of the high mortality rate and severe morbidities that occurs after the SSIH, it is mandatory to identify and apply standardized treatment strategies for patients.

Keywords: Stroke, spontaneous intracerebral hematoma, intracerebral hematoma score, treatment

\section{INTRODUCTION}

Intracerebral hemorrhages constitute $6.5 \%-19.9 \%$ of all stroke causes (1). Spontaneous supratentorial intracerebral hematomas (SSIH) are among the pathologies that cause serious mortality and morbidity; however, there is still no consensus regarding their treatment (2). To date, several studies have compared conservative and surgical treatments, including current treatment approaches (3-5). Based on the literature review, conventional surgical treatment can be considered to have better results for superficial and small SSIHs than conservative treatments, and minimally invasive surgical methods have more favorable results in deep-seated SSIHs. Therefore, in this study, we aimed to investigate the demographic and clinical characteristics, treatment approaches, and outcomes of patients with SSIH treated in our clinic.

\section{METHODS}

Patients with intracerebral hematoma admitted to our emergency department between December 2017 and December 2018 were retrospectively reviewed. A total of 108 patients diagnosed with SSIH using computed tomography (CT) scans were included in this study. Patients with trauma, aneurysm, vascular malformation, and hematomas due to tumor pathology and similar etiologies were excluded. In addition, patients with posterior fossa 
hematomas were also excluded from this study due to differences in clinical features and treatment approach. Medical history (in some cases, of patients' relatives) and demographic information were obtained, and detailed neurological examinations were performed. The neurological status of the patients was evaluated using the Glasgow Coma scale (GCS) in the emergency department, and the first prognostic evaluation was performed (6). Arterial blood pressure measurements and biochemical tests were performed to exclude possible differential diagnoses. Metabolic parameters (glucose, electrolytes, and creatinine) and hematologic parameters (complete blood count, prothrombin time, international normalized ratio, and partial thromboplastin time) were analyzed through blood examinations. The hematoma volume, hemispheric side (right or left), location (deep or lobar), lobe (frontal, temporal, parietal, insular, occipital), and intraventricular hemorrhage were determined using CT. Hematoma volume was calculated according to the $A B C / 2$ rule (7). A midline shift of $>5 \mathrm{~mm}$ was considered positive. The Intracerebral Hematoma score (IHS) was calculated and recorded (8). After these stages, the treatment plan was firstly determined. As surgical intervention, patients underwent hematoma evacuation by craniotomy or decompressive craniectomy or external ventricular drainage (EVD) for intraventricular hemorrhage. Conservatively treated patients were monitored during the post-hospitalization follow-up. The multimodal treatment for these patients was planned in collaboration with the anesthesiology and neurology departments. Mortality rates were calculated by comparing two different treatment methods. This retrospective study was performed in accordance with the ethical standards provided by the Helsinki Declaration. Informed consent form was obtained from all patients.

\section{Statistical Analysis}

The results for continuous variables are provided as mean \pm standard deviation (SD). The Kolmogorov-Smirnov test was used to evaluate the distribution normality of continuous variables. Student's t-test or Mann-Whitney U test was used to compare independent continuous variables between the two groups depending on whether the statistical hypotheses were fulfilled. A $p$ value of $<0.05$ was considered statistically significant. SPSS 22.0 program (IBM Software, New York, USA) was used for analysis.

\section{RESULTS}

The demographic, clinical, radiological, and prognostic characteristics of 108 patients [ 57 (52.8\%) men and 51 (47.2\%) women] are shown in Table 1. Among them, 89 (82.4\%) patients were treated conservatively and 19 (17.6\%) were treated surgically. As the mean age was $64.5 \pm 14.0$ (mean value \pm SD) years, the age and sex distribution of treatment groups was not statistically significant $(p>0.05)$. The mean GCS was $12.3 \pm 3.0$, which was significantly lower in the surgical group than in the conservative group $(p<0.05)$.

About $84.2 \%$ of patients had arterial hypertension on admission. However, no significant difference was observed between the treatment groups with respect to comorbidities $(p>0.05)$. The mean hematoma volume was $40.1 \pm 51.6 \mathrm{~mL}$, which was significantly higher in the surgical group than in the conservative group $(p<0.05)$. Intraventricular hemorrhage and midline shift positivity were significantly higher in the surgical group $(p<0.05)$. However, the difference in the hemisphere side (right/left) and location (deep/lobar) of the hematoma was not significant between the treatment groups $(p>0.05)$. The patients' mean IHS was 1.3 \pm 1.4 . Table 2 shows IHS according to the treatment groups. The IHS score was significantly higher in the surgical group than in the conservative group $(p<0.05)$. Table 3 shows the mortality rates, which were significantly higher in the surgical group during the first month, sixth month, and first year than those in the conservative group $(p<0.05)$.

\section{DISCUSSION}

$\mathrm{SSIH}$, also known as primary intracerebral hematomas, constitute $78 \%-88 \%$ of intracerebral hemorrhages $(9,10)$. In regard to their pathogenesis, they were considered to occur with spontaneous rupture due to small arterial or arteriole wall damage caused by hypertension or amyloid angiopathy $(10,11)$.

The incidence of intracerebral hematoma in elderly patients $(>65$ years) was higher than that in other age groups $(12,13)$. However, whether sex is a risk factor or not remains controversial (13-15). Different results have been claimed to be obtained from different populations or countries. In this study, 57 (52.7\%) patients were older than 65 years, with a mean age of 64.5 years. Furthermore, no significant difference in age and sex was observed between the treatment groups.

The most common risk factor for SSIHs is hypertension, which is responsible for the etiology in approximately $60 \%-70 \%$ of patients $(16,17)$. Qureshi et al. (10) reported that intracerebral hematomas occurring due to hypertension are frequently located in the basal ganglia. Sacco et al. (13) reported in their case series of 549 patients that $75.6 \%$ had hypertension and similar rates of SSIH localization (deep or lobar) were also determined. In this study, hypertension was observed in $84.2 \%$ of patients. However, patients with lobar hematoma were found to be more hypertensive with a slight difference (55.6\%). 
In the literature, various studies on the SSIH treatment that proposed different treatment features have been conducted. The World Health Organization treatment guidelines, prepared almost 30 years ago, only recommended surgical treatment for large-volume SSIHs (18), whereas at the same time studies have also suggested the surgery-only treatment approach for small subcortical SSIHs (3). Multiple attempts have been made to eliminate this uncertainty, and large multicenter randomized clinical trials have already been conducted. The first and best known is the STICH study, published in 2005 (19). According to the results of this study, early surgery is not more effective than conservative treatment. However, when subgroups such as superficial (lobar) intracerebral hematomas (not the focus of this study) were examined, early surgery was found to provide better results than conservative treatment. In the following years, the STICH 2 study was conducted as a continuation study

\begin{tabular}{|c|c|c|c|c|c|}
\hline & & Total & Conservative group & Surgery group & $p$ value \\
\hline \multicolumn{6}{|l|}{ Demographic features } \\
\hline Age & $(\mathrm{M} \pm \mathrm{SD})$ & $64.5 \pm 14.0$ & $64.7 \pm 13.7$ & $63.5 \pm 15.8$ & $>0.05^{\mathrm{t}}$ \\
\hline \multicolumn{6}{|l|}{ Sex } \\
\hline Male & $(n, \%)$ & $57,52.8 \%$ & $47,52.8 \%$ & $10,52.6 \%$ & \multirow[t]{2}{*}{$>0.05^{x^{2}}$} \\
\hline Female & $(n, \%)$ & $51,47.2 \%$ & $42,47.2 \%$ & $9,47.4 \%$ & \\
\hline \multicolumn{6}{|l|}{ Clinical features } \\
\hline Initial GCS & $(\mathrm{M} \pm \mathrm{SD})$ & $12.3 \pm 3.0$ & $13.0 \pm 2.4$ & $9.2 \pm 3.5$ & $<0.05^{\mathrm{m}}$ \\
\hline 3-8 & $(n, \%)$ & $14,13.0 \%$ & $5,5.6 \%$ & $9,47.4 \%$ & \multirow{3}{*}{$<0.05^{x^{2}}$} \\
\hline $9-12$ & $(n, \%)$ & $25,23.1 \%$ & $20,22.5 \%$ & $5,26.3 \%$ & \\
\hline $13-15$ & $(n, \%)$ & $69,63.9 \%$ & $64,71.9 \%$ & $5,26.3 \%$ & \\
\hline \multicolumn{6}{|l|}{ Comorbidities } \\
\hline $\mathrm{HT}+$ & $(n, \%)$ & $91,84.2 \%$ & $75,69.4 \%$ & $16,84.2 \%$ & $>0.05 x^{2}$ \\
\hline $\mathrm{DM}+$ & $(n, \%)$ & $22,20.3 \%$ & $18,16.6 \%$ & $4,21.0 \%$ & $>0.05^{x^{2}}$ \\
\hline$A C+a$ & $(n, \%)$ & $49,45.3 \%$ & $37,34.2 \%$ & $9,47.3 \%$ & $>0.05 x^{2}$ \\
\hline \multicolumn{6}{|l|}{ Radiological features } \\
\hline Hematoma volume $(\mathrm{mL})$ & $(\mathrm{M} \pm \mathrm{SD})$ & $40.1 \pm 51.6$ & $27.5 \pm 38.3$ & $99.5 \pm 64.5$ & $<0.05^{\mathrm{m}}$ \\
\hline \multicolumn{6}{|l|}{$\mathrm{IVH}$} \\
\hline- & $(n, \%)$ & $78,72.2 \%$ & $76,85.4 \%$ & $2,10.5 \%$ & \multirow[t]{2}{*}{$<0.05^{x^{2}}$} \\
\hline+ & $(n, \%)$ & $30,27.8 \%$ & $13,14.6 \%$ & $17,89.5 \%$ & \\
\hline \multicolumn{6}{|l|}{ Midline shift } \\
\hline- & $(\mathrm{n}, \%)$ & $81,75.0 \%$ & $75,84.3 \%$ & $6,31.6 \%$ & \multirow[t]{2}{*}{$<0.05^{x^{2}}$} \\
\hline+ & $(n, \%)$ & $27,25.0 \%$ & $14,15.7 \%$ & $13,68.4 \%$ & \\
\hline \multicolumn{6}{|l|}{ Hemispheric side } \\
\hline Right & $(n, \%)$ & $52,48.1 \%$ & $40,44.9 \%$ & $12,63.2 \%$ & $>0.05^{x^{2}}$ \\
\hline Left & $(n, \%)$ & $55,50.9 \%$ & $48,53.9 \%$ & $7,36.8 \%$ & $>0.05 x^{2}$ \\
\hline Bilateral & $(n, \%)$ & $1,0.9 \%$ & $1,1.1 \%$ & $0,0.0 \%$ & $>0.05 x^{2}$ \\
\hline \multicolumn{6}{|l|}{ Location } \\
\hline Lobarb & $(n, \%)$ & $60,55.6 \%$ & $47,52.8 \%$ & $13,68.4 \%$ & $>0.05 x^{2}$ \\
\hline Deep & $(n, \%)$ & $48,44.4 \%$ & $42,47.2 \%$ & $6,31.6 \%$ & $>0.05 x^{2}$ \\
\hline \multicolumn{6}{|l|}{ Prognosis } \\
\hline IHS & $(\mathrm{M} \pm \mathrm{SD})$ & $1.3 \pm 1.4$ & $0.9 \pm 1.2$ & $2.8 \pm 1.1$ & $<0.05^{\mathrm{m}}$ \\
\hline Follow-up (day) & $(\mathrm{M} \pm \mathrm{SD})$ & $358.9 \pm 265.6$ & $410.9 \pm 250.5$ & $268.6 \pm 308.3$ & $>0.05^{\mathrm{m}}$ \\
\hline \multicolumn{6}{|c|}{$\begin{array}{l}\text { alncludes all anticoagulant-antiaggregant treatments used during hospital admission, bstatistical analysis was performed for each lobe separately, but since there was no } \\
\text { significant difference, the results were reported under a } 2 \text { single heading, tt- test, }{ }^{2} \text { Chi-square test, mMann-Whitney U test, M: Mean, SD: Standard deviation, n: Number of } \\
\text { patients, GCS: Glasgow Coma score, HT: Hypertension, DM: Diabetes mellitus, AC: Anticoagulant, mL: Milliliter, IVH: Intraventricular hemorrhage, IHS: Intracerebral Hematoma } \\
\text { score }\end{array}$} \\
\hline
\end{tabular}


with a focus on this subject, and the results were published (4). In support of subgroup results in the first STICH study, early surgery has been found to have a clinically significant advantage over conservative treatment, especially in lobar hematomas without intraventricular hemorrhage. In the literature, studies have also investigated the appropriate surgical treatment methods for deeply located and/or with ventricular opening intracerebral hematomas. Several recent studies have been performed, and some of them were successfully conducted, especially with minimally invasive surgery (endoscopic surgery), hematoma drainage, or clot removing techniques $(5,20-23)$. However, most of these specialized technical equipment and medications are not available for all treatment centers, and because intracerebral hematomas are considered as emergency neurosurgical pathology, deciding the timing of surgery and choosing the appropriate treatment option are extremely important. Although surgical indications for intracerebral hematomas were not standardized, our approach was to evacuate the hematoma in patients with high-volume lobar hematomas with low-onset GCS and midline shift (risk of brain herniation). Decompressive craniectomy was performed in a deeply located hematoma in the worse clinical situation. EVD was performed to prevent complications such as acute hydrocephalus.

IHS is a scoring system used to gain insight on the prognosis of patients with intracerebral hematoma but does not have an effect on surgical decision (8). The focus of this study is

\begin{tabular}{|l|l|l|l|}
\hline \multicolumn{4}{|l|}{ Table 2. IHS values of treatment groups } \\
\hline IHS & Conservative group & Surgery group & Total \\
\hline 0 & 47 & 0 & 47 \\
\hline 1 & 17 & 2 & 19 \\
\hline 2 & 11 & 5 & 16 \\
\hline 3 & 11 & 8 & 19 \\
\hline 4 & 3 & 2 & 5 \\
\hline 5 & 0 & 2 & 2 \\
\hline IHS: Intracerebral Hematoma score & \\
\hline
\end{tabular}

Table 3. Mortality rates of treatment groups

\begin{tabular}{|l|l|l|l|l|}
\hline & $\begin{array}{l}\text { Conservative } \\
\text { group }\end{array}$ & $\begin{array}{l}\text { Surgery } \\
\text { group }\end{array}$ & Total & $p$ value \\
\hline $\begin{array}{l}\text { Mortality } \\
\text { (1. month) }\end{array}$ & $15.3 \%$ & $52.6 \%$ & $22.2 \%$ & $<0.05 x^{2}$ \\
\hline $\begin{array}{l}\text { Mortality } \\
\text { (6. months) }\end{array}$ & $24.7 \%$ & $57.8 \%$ & $30.5 \%$ & $<0.05 x^{2}$ \\
\hline $\begin{array}{l}\text { Mortality } \\
\text { (12. months) }\end{array}$ & $26.9 \%$ & $63.1 \%$ & $42.5 \%$ & $<0.05 x^{2}$ \\
\hline$x^{2}$ Chi-square test & \multicolumn{5}{|l|}{} \\
\hline
\end{tabular}

not on developing a new scoring system. However, as seen in the literature, there is no standardized clinical prognostic classification (24-26). Upon the evaluation of the results in this study, the mean IHS was found to be 1.3 1.4. IHS in the surgical group was higher than that in the conservative group. Although the midline shift is one of the most helpful findings for the surgeon to plan the surgical treatment of these pathologies, it is not used in calculating IHS. We consider that this finding may also be an important criterion for the life expectancy and prognosis of patients with $\mathrm{SSIH}$ after 1 month and that such modification can be made.

The 1-year mortality of patients was high (42.5\%), as shown in Table 3. However, this is believed to be not due to the primary effect of the hematoma but rather due to comorbidities. Alsumrain et al. (27) reported that patients with SSIH more frequently have pneumonia. In addition, although not the focus of this study, the most important feature of SSIHs is the presence of comorbidities, such as hemiparesis, hemiplegia, and spasticity, even in patients with good prognosis. Patients with neurological dysfunction are more likely to die due to other causes.

This study has some limitations. First, intracerebral hematomas were evaluated as one of the emergency neurosurgical pathologies with controversial surgical treatment based on our own perspective. Second, this was a single-centered study, and therefore, the incidence-prevalence of the disease was not determined. Finally, although this was a retrospective study, all patients with intracerebral hematoma admitted to our emergency department underwent the standardized diagnostic, radiological, and clinical examination.

\section{CONCLUSION}

$\mathrm{SSIH}$ is a pathology with a high mortality rate and causes various neurological disorders and severe comorbidities even in non-lifethreatening conditions, which worsens the quality of life. The standardization of current diagnosis and treatment algorithms can significantly improve the survival and quality of life of these patients.

\section{Ethics}

Ethics Committee Approval: This retrospective study was performed in accordance with the ethical standards provided by the Helsinki Declaration.

Informed Consent: Informed consent form was obtained from all patients.

Peer-review: Externally peer-reviewed. 
Financial Disclosure: The author declared that this study received no financial support.

\section{REFERENCES}

1. Feigin VL, Lawes CM, Bennett DA, Anderson CS. Stroke epidemiology: a review of population-based studies of incidence, prevalence, and casefatality in the late 20th century. Lancet Neurol 2003;2:43-53.

2. Hemphill JC 3rd, Greenberg SM, Anderson CS, Becker K, Bendok BR, Cushman $\mathrm{M}$, et al. Guidelines for the management of spontaneous intracerebral hemorrhage: a guideline for healthcare professionals from the American Heart Association/American Stroke Association. Stroke 2015;46:2032-60.

3. Unwin DH, Batjer HH, Greenlee RG Jr. Management controversy: medical versus surgical therapy for spontaneous intracerebral hemorrhage. Neurosurg Clin N Am 1992;3:533-7.

4. Mendelow AD, Gregson BA, Rowan EN, Murray GD, Gholkar A, Mitchell PM, et al. Early surgery versus initial conservative treatment in patients with spontaneous supratentorial lobar intracerebral haematomas (STICH II): a randomised trial. Lancet 2013;382:397-408.

5. Hanley DF, Thompson RE, Muschelli J, Rosenblum M, McBee N, Lane K, et al. Safety and efficacy of minimally invasive surgery plus alteplase in intracerebral haemorrhage evacuation (MISTIE): a randomised, controlled, open-label, phase 2 trial. Lancet Neurol 2016;15:1228-37.

6. Teasdale G, Jennett B. Assessment of coma and impaired consciousness. A practical scale. Lancet 1974;2:81-4.

7. Kothari RU, Brott T, Broderick JP, Barsan WG, Sauerbeck LR, Zuccarello $M$, et al. The ABCs of measuring intracerebral hemorrhage volumes. Stroke 1996;27:1304-5.

8. Hemphill JC 3rd, Bonovich DC, Besmertis L, Manley GT, Johnston SC. The ICH Score: a simple, reliable grading scale for intracerebral hemorrhage. Stroke 2001;32:891-7.

9. Foulkes MA, Wolf PA, Price TR, Mohr JP, Hier DB. The Stroke Data Bank: design, methods, and baseline characteristics. Stroke 1988;19:547-54.

10. Qureshi AI, Tuhrim S, Broderick JP, Batjer HH, Hondo H, Hanley DF. Spontaneous intracerebral hemorrhage. N Engl J Med 2001;344:145060.

11. Sutherland GR, Auer RN. Primary intracerebral hemorrhage. J Clin Neurosci 2006;13:511-7.

12. Ariesen MJ, Claus SP, Rinkel GJ, Algra A. Risk factors for intracerebral hemorrhage in the general population: a systematic review. Stroke 2003;34:2060-5.

13. Sacco S, Marini C, Toni D, Olivieri L, Carolei A. Incidence and 10-year survival of intracerebral hemorrhage in a population-based registry. Stroke 2009;40:394-9.

14. Suh I, Jee SH, Kim HC, Nam CM, Kim IS, Appel LJ. Low serum cholesterol and haemorrhagic stroke in men: Korea Medical Insurance Corporation Study. Lancet 2001;357:922-5.
15. Iribarren C, Jacobs DR, Sadler M, Claxton AJ, Sidney S. Low total serum cholesterol and intracerebral hemorrhagic stroke: is the association confined to elderly men? The Kaiser Permanente Medical Care Program. Stroke 1996;27:1993-8.

16. Fewel ME, Thompson BG Jr, Hoff JT. Spontaneous intracerebral hemorrhage: a review. Neurosurg Focus 2003;15:1.

17. Thrift AG, McNeil JJ, Forbes A, DonnanGA. Three important subgroups of hypertensive persons at greater risk of intracerebral hemorrhage. Melbourne Risk Factor Study Group. Hypertension 1998;31:1223-9.

18. No authors listed. Stroke--1989. Recommendations on stroke prevention, diagnosis, and therapy. Report of the WHO Task Force on Stroke and other Cerebrovascular Disorders. Stroke 1989;20:1407-31.

19. Mendelow AD, Gregson BA, Fernandes HM, Murray GD, Teasdale GM, Hope DT, et al. Early surgery versus initial conservative treatment in patients with spontaneous supratentorial intracerebral haematomas in the International Surgical Trial in Intracerebral Haemorrhage (STICH): a randomised trial. Lancet 2005;365:387-97.

20. Mould WA, Carhuapoma JR, Muschelli J, Lane K, Morgan TC, Mcbee NA, et al. Minimally invasive surgery plus recombinant tissue-type plasminogen activator for intracerebral hemorrhage evacuation decreases perihematomal oedema. Stroke 2013;44:627-34.

21. Webb AJ, Ullman NL, Mann S, Muschelli J, Awad IA, Hanley DF. Resolution of intraventricular hemorrhage varies by ventricular region and dose of intraventricular thrombolytic: The Clot Lysis: Evaluating Accelerated Resolution of IVH (CLEAR IVH) Program. Stroke 2012;43:1666-8.

22. Ziai WC, Tuhrim S, Lame K, Mcbee N, Lees K, Dawson J, et al. A multicenter, randomized, double-blinded, placebo-controlled phase III Study of Clot Lysis Evaluation of Accelerated Resolution of Intrventricular Hemorrhage (CLEAR III). Int J Stroke 2014;9:536-42.

23. Webb AJ, Ullman NL, Morgan TC, Muschelli J, Kornbluth J, Awad IA, et al . Accuracy of the ABC/2 Score for Intracerebral Hemorrhage: Systematic Review and Analysis of MISTIE, CLEAR-IVH, and CLEAR III. Stroke 2015;46:2470-6.

24. Cheung RT, Zou LY. Use of the original, modified, or new intracerebral hemorrhage score to predict mortality and morbidity after intracerebral hemorrhage. Stroke 2003;34:1717-22.

25. Ruiz-Sandoval JL, Chiquete E, Romero-Vargas S, Padilla-Martínez JJ, González- Cornejo S. Grading scale for prediction of outcome in primary intracerebral hemorrhages. Stroke 2007;38:1641-4.

26. Rost NS, Smith EE, Chang Y, Snider RW, Chanderraj R, Schwab K, et al. Prediction of functional outcome in patients with primary intracerebral hemorrhage: The FUNC score. Stroke 2008;39:2304-9.

27. Alsumrain M, Melillo N, Debari VA, Kirmani J, Moussavi M, Doraiswamy $\mathrm{V}$, et al. Predictors and outcomes of pneumonia in patients with spontaneous intracerebral hemorrhage. J Intensive Care Med 2013;28:118-23. 